\title{
Análise de Stakeholders Aplicada em Órgãos Públicos: o caso da Secretaria de Estado do Turismo do Paraná
}

\author{
Saulo Fabiano Amâncio Vieira $1^{1}$ \\ Benny Kramer Costa ${ }^{2}$ \\ João Maurício Gama Boaventura ${ }^{3}$
}

\section{Resumo}

O presente artigo tem por objetivo analisar a atuação dos stakeholders no desenvolvimento de atividades estratégicas da Secretaria de Estado do Turismo do Paraná (SETU), verificados sob a óptica da teoria do stakeholders. Para tanto, realizouse ainda uma revisão acerca da teoria dos stakeholders descrevendo sua evolução conceitual e modelos de análise utilizados. Em relação ao delineamento da pesquisa temse que a mesma se caracteriza pela aplicação de uma pesquisa exploratória, qualitativa, desenvolvida por meio de um estudo de caso único, representado pelo órgão estadual de turismo do Paraná (SETU). Sobre quem são os stakeholders da SETU verificou-se que aqueles que possuem maior relevância foram identificados numa listagem com oito instituições pertencentes ao Conselho Consultivo do Turismo do Paraná. Conclui-se que a atuação dos stakeholders junto à definição das políticas e estratégias da SETU ocorre via Conselho Consultivo o Turismo e suas cinco Câmaras Temáticas. Foi verificado ainda que muitos dos membros do Conselho ainda possuem baixa participação nesses órgãos colegiados, porém, há uma evolução de sua participação desde a sua criação no ano de 2003.

Palavras-chave: Teoria dos Stakeholders. Turismo. Estratégia.

\footnotetext{
1 Doutor em Administração pela Universidade Nove de Julho - UNINOVE. Professor do Programa de Pós-Graduação em Administração da Universidade Estadual de Londrina - UEL - PPGA/UEL. End.: Rodovia Celso Garcia Cid, PR 445 - Km 380, Campus Universitário, Londrina - PR. CEP: 86051-980 - Brasil. E-mail: saulo@uel.br.

2 Pós-doutor e Doutor em Administração pela Faculdade de Economia, Administração e Contabilidade - FEA da Universidade de São Paulo - USP. Professor do Programa de Mestrado e Doutorado em Administração da Universidade Nove de Julho - UNINOVE. End.: Avenida Francisco Matarazzo, 612 - 1º andar, Prédio Água Branca, São Paulo - SP. CEP: 05001-100 - Brasil. E-mail: bennycosta@yahoo.com.br.

3 Doutor em Administração pela Faculdade de Economia, Administração e Contabilidade - FEA da Universidade de São Paulo USP. Professor da Faculdade de Economia, Administração e Contabilidade - FEA da Universidade de São Paulo - USP. End.: Av. Prof. Luciano Gualberto, 908 - sala E-201, São Paulo - SP. CEP: 05508-010 - Brasil. E-mail: jboaventura@usp.br.

Artigo recebido em: 08/02/2011. Aceito em: 19/08/2011. Membro do Corpo Editorial Científico responsável pelo processo editorial: Rolando Juan Soliz Estrada.
}

(c) (i) () $)$ Esta obra está sob uma Licença Creative Commons Atribuição-Uso. 


\section{Introdução}

No Brasil, no ano de 2003, ocorreu a criação de um Ministério exclusivo para o Turismo, Ministério do Turismo (MTUR), refletindo a importância que o segmento está conquistando no país. Teve como marcos a elaboração do Plano Nacional de Turismo, bem como o setor teve sua importância ratificada em termos estaduais no mesmo com a implementação de Secretarias de Estado, que mais especificamente no Paraná foi criada a Secretaria de Estado do Turismo do Paraná (SETU). Essa Secretaria tem como principal objetivo planejar o desenvolvimento do Turismo no Paraná, através da estruturação de uma Política Estadual de Turismo conjuntamente com o trade turístico local (PARANÁ, 2008). Ou seja, conjuntamente com a estruturação tanto do Ministério do Turismo quanto da SETU, tinha-se implícito nesse processo o trabalho dos diversos stakeholders para a definição, implementação e acompanhamento das estratégias públicas do turismo no Paraná.

Dessa forma, a necessidade de maior participação e compreensão nos processos decisórios pelos stakeholders do setor turístico, relacionados à sua dinâmica de atuação na condução de atividades estratégicas pode ser transposta para o setor público que possui estreita convivência com as incertezas que emanam do ambiente e que necessitam ser incorporadas nas ações organizacionais. O trabalho é proposto no sentido de preencher lacunas, no que se refere à carência de estudos na área de gestão turística, mais especificamente sobre a atuação dos stakeholders no desenvolvimento de atividades estratégicas da SETU, onde se pretende observar, compreender e delinear suas experiências. A presente pesquisa tem como objetivo analisar a atuação dos stakeholders no desenvolvimento de atividades estratégicas da Secretaria de Estado do Turismo do Paraná (SETU). Para tanto, formulou-se as seguintes questões de pesquisa: quem são e quais as características dos stakeholders? Quais são seus recursos e motivações? Como se dá a atuação dos stakeholders na perspectiva da SETU? Para elucidar tais processos será realizada a análise sob a perspectiva da teoria dos stakeholders.

O termo stakeholders, ao longo dos últimos 46 anos, tem sido definido e, por conseguinte, estudado com maior ênfase, envolvendo diversos periódicos acadêmicos de renome internacionais como Business Ethics Quartely, Critical Perspectives in Accounting, Academyof Management Reviewe Academy of Management Journal dentre outras, que têm se dedicado a elaboração e dis- 
cussão do assunto, assim como tem lançado diversos questionamentos na área (FRIEDMAN; MILES, 2006).

Na literatura gerencial a temática sobre stakeholders vem sendo abordada a partir da publicação de Richard E. Freeman em 1984, Strategic Management: a Stakeholder Approach (1984). Desde então a gestão dos stakeholders é frequentemente apontada como um fator crítico de sucesso. A definição clássica de stakeholder é "[...] qualquer grupo ou pessoa cujos interesses podem afetar ou ser afetados pelas realizações dos objetivos de uma organização." (FREEMAN 1984, p. 46). Freeman (1984) relata ainda que a suposição principal da teoria dos stakeholders é aquela cuja eficácia da organização é medida por sua habilidade de satisfazer não somente os acionistas, mas aqueles que têm um vínculo com a organização.

No que se refere às definições do termo stakeholders, 55 delas foram levantadas em 75 publicações, entre os anos de 1963 e 2003, por Friedman e Miles (2006); sendo que todas tomam a organização como o centro das discussões. Quanto aos trabalhos realizados sobre o tema stakeholders, Laplume, Sonpar e Litz (2008) ao elaborarem um estudo sobre a literatura teórica e acadêmica produzida sobre os stakeholders, apontam a necessidade de mais investigação empírica em um vasto conjunto de organizações, um maior número de pesquisas qualitativas para documentar aspectos cognitivos da forma como gestores respondem a expectativas dos stakeholders, e um retorno às teorias que dão ênfase aos benefícios estratégicos da gestão dos stakeholders, com uma visão mais ampla em relação ao desempenho das organizações.

Esses aspectos, em seu conjunto, têm contribuído para a evolução dos estudos relacionados ao tema stakeholders, assim como permite induzir a realização de novos trabalhos em organizações e setores econômicos até então pouco explorados ou sem ter sido alvo de qualquer estudo em relação à atuação de seus stakeholders, podendo ser aplicado na análise do setor turístico em organizações públicas.

Para tanto, o presente artigo está estruturado em introdução, fundamentação teórica, procedimentos metodológicos, apresentação e análise dos dados e finaliza com as considerações finais. 


\section{Fundamentação Teórica}

Diversos estudiosos têm abordado ao longo dos anos temas e pesquisas relacionadas à análise dos stakeholders, tais como: Freeman (1984); Friedman e Miles (2006); Mitroff (1983); Mitchell, Agle e Wood (1997); Reed, Graves e Dandy (2009); Prell, Hubacek e Reed (2009); Lambert, Pajunen e Parvinen (2008); Medilanski, Chuan e Mosler (2007); Hermans e Thissen (2009); Reed (2008); e Friedman e Mason (2004).

Freeman (1984) mostra que a descrição dos tipos de stakeholders, pelo ponto de vista da firma, corresponde aos seguintes atores: proprietários, defensores dos consumidores, consumidores, competidores, mídia, empregados, grupos de interesses especiais, ambientalistas, fornecedores, governantes e as organizações comunitárias locais.

Conforme descrevem Friedman e Miles (2006), as definições de stakeholder geralmente esclarecem o conceito de stakeholder das seguintes formas: (a) Inicialmente, indicam o tipo de conexão entre organizações e stakeholders, que normalmente fica evidente por um verbo, como, por exemplo, o emprego do verbo afetar na definição de Freeman (1984), que pode ser classificado como amplo, enquanto outras definições também possuem verbos amplos e relativamente neutros como impactar, influenciar, interagir; (b) Entretanto, alguns verbos descrevem mais precisamente o tipo de relação, como responsabilizar, apoiar, depender, darsignificado, arriscaralgo de valorouinvestir, (revelando os interesses).

Freeman (1984) também descreve o processo de formulação de estratégias para os stakeholders que se centram nos seguintes pontos: (1) análise de seu comportamento; (2) explanação de seu comportamento; (3) análise de coalização; (4) estratégicas genéricas (avaliação das forças estratégicas); (5) programas específicos para os stakeholders; e (6) programa de integração dos stakeholders.

No que tange ao processo de caracterização do comportamento dos stakeholders, Mitroff (1983, p.36) descreve que estes podem ser caracterizados nas seguintes categorias:

As propostas e as motivações; Os recursos impostos, que podem ser: material, simbólico, físico, status, informacional, habilidade; Conhecimentos específicos e opiniões; Compro- 
metimentos de ordem legal e de outros tipos; Relacionamentos com outros stakeholders no sistema em virtude do poder, autoridade, responsabilidade e controle (MITROFF, 1983, p. 36).

Em relação ao processo de identificação dos stakeholders, Mitchell,Agle e Wood (1997, p.854) apresentam a proposição de um modelo sustentado em três dimensões: "(1) o poder dos stakeholders de influenciar a empresa, (2) a legalidade do stakeholder no relacionamento com a empresa, e (3) a urgência do stakeholder de reivindicação na empresa". As bases das três dimensões são tratadas como segue. Gomes (2004) descreve a percepção de Mitchell, Agle e Wood (1997) da seguinte maneira: Poder: sugeriu que o poder fosse provável resultar de três dimensões contextuais: poder normativo, poder coercitivo, $e$ poder utilitário. Urgência: a urgência possui muitos significados, mas nos termos de gerência de stakeholders pode-se ver em consequência da sensibilidade e da criticidade do tempo. Legalidade: considerada uma dimensão crítica na identificação de um stakeholder, verifica-se que, às vezes, um ator tem uma estaca na organização mas essa demanda não é legal nem moral (somente os atores que têm estacas legítimas devem ser considerados stakeholders). Para tal, definem a legalidade como

[...] uma percepção generalizada ou suposição que as ações de uma entidade são desejáveis, apropriado, ou aproprie dentro de alguns sistemas social construídos de normas, de valores, de opinião, e de definições (SUCHMAN apud MITCHELL, AGLE; WOOD, 1997, p. 866).

Reed, Graves e Dandy (2009) comentam que a análise de stakeholders foi desenvolvida em diferentes campos e para finalidades diferentes, conduzindo à confusão sobre o conceito e a prática da análise. Para tanto, os autores formularam a seguinte questão: como e porque a análise de stakeholders deve ser conduzida para a pesquisa de gestão participativa dos recursos naturais? Os autores discutem a base teórica normativa e instrumental para a análise de stakeholders, e uma tipologia da análise da parte interessada é proposta. Isto consiste em métodos para: i) identificar stakeholders; ii) diferenciar os mesmos categorizando-os; e iii) verificar relacionamentos de investigação entre stakeholders. Esses métodos e aproximações são ilustrados então com uma série de estudos de caso financiados com o programa da economia rural e da 
utilização da terra (RELU). Estes estudos de caso mostram a escala ampla dos métodos participativos e não-participativos que podem ser usados, e discutem alguns dos desafios e das limitações de métodos existentes para a análise da parte interessada.

Para Prell, Hubacek e Reed (2009), o uso crescente da análise de stakeholders na gerência de recurso natural reflete um reconhecimento crescente que estes possam e devam influenciar a tomada de decisão ambiental. Para os autores a análise dos stakeholders pode ser usada para evitar conflitos, assegura-se que a marginalização de determinados grupos não esteja reforçada, $e$ para representar razoavelmente interesses diversos. Foi realizado um estudo de caso No Parque Nacional no Reino Unido, onde foi usada a análise de rede social para informar a análise da parte interessada. Essa informação auxiliou a identificar que indivíduos e categorias de parte interessada postaram papers fundamentais na rede e quais eram mais periféricos. Tal procedimento contribuiu para as etapas seguintes de seleção da parte interessada, as extremidades do artigo com uma discussão nas forças e limitações a se combinar a análise de rede social com a análise de stakeholders.

Lamberg, Pajunen e Parvinen (2008) disponibilizaram um modelo de processo explanatório da gerência de stakeholders, que pode também ser utilizada na analise de stakeholders. O modelo mostra como e porque a dependência de recursos é manifestada em edições de gerência de stakeholders. Para tanto realizou-se um estudo de caso longitudinal na United Airlines e na fusão abandonada de vias aéreas dos EUA de 2000-2001. Segundos os autores, a análise demonstra que as circunstâncias iniciais estão acentuadas pela sequência de ações, oferecendo uma explanação plausível para resultados do processo, ou seja, devem-se analisar os enlaces dos mesmos durante iniciativas estratégicas para que não haja agravamento de conflitos durante o processo.

Medilanski, Chuan e Mosler (2007) conduziram um estudo das barreiras institucionais a introduzir a separação de esgoto na área urbana de Kunming, China. Com base em uma análise de stakeholders, foram construídos os diagramas que mostram a importância relativa do poder de tomada de decisão e do interesse sobre o assunto. Os resultados da tomada de decisão foram avaliados por todos os stakeholders. Os autores concluíram que embora um número de stakeholders preliminares tivesse um grande interesse na separação do esgoto em um contexto urbano, a maioria das partes interessadas era relutante a essa ideia. Em termos metodológicos foi desenvolvido uma aproximação para cor- 
roborar uma análise com a percepção dos stakeholders por eles mesmos. Os autores concluíram que o desacordo com a suposição da maioria de teorias da política, stakeholders locais consideram caminhos informais da decisão de grande importância.

De acordo com Hermans e Thissen (2009), os analistas da política de interesse público usam os métodos enraizados dentro OU e a análise de sistemas para suportar desenvolvedores de política em seu julgamento. Ao fazer assim, a maioria dos analistas de políticas reconhece o valor de alguma compreensão do papel dos atores em processos políticos. Os métodos diferentes estão disponíveis para ajudar a tal compreensão e, embora todo o foco em atores, tenham diferenças importantes entre eles. A introspecção na escala de métodos disponíveis e de suas características ajudará assim analistas de políticas a aprender mais sobre o potencial e as limitações envolvidos em analisar processos incluindo vários agentes. O presente trabalho forneceu tal visão geral, baseada nas exigências que os principais métodos devem cumprir. Essa visão geral é usada para discutir algumas das implicações para os analistas de política que estão interessados em analisar os processos incluindo vários agentes, se centrando especificamente sobre trade-offs entre a qualidade analítica e a usabilidade prática.

De acordo com Reed (2008), os problemas ambientais exigem uma tomada de decisão flexível e transparente já que a participação dos stakeholders tem sido utilizada cada vez mais e encaixado na política nacional e internacional. A revisão do autor segue primeiramente o desenvolvimento de aproximações participativas em contextos disciplinares e geográficos diferentes, e revê as tipologias que podem ser usadas para categorizar e selecionar métodos participativos. O autor revê então a evidência para benefícios normativos e pragmáticos da participação, e avalia limitações e inconvenientes. Oito características da participação da melhor prática são identificadas então de uma análise sustentada na teoria. Reed discute ainda que a participação do stakeholder precisa ser sustentada por uma filosofia que vise a concessão, a equidade, a confiança e a aprendizagem. A participação dos stakeholders deve ser considerada o mais cedo possível e durante todo o processo, não podendo negligenciar seus pleitos ao longo do processo. Ao final, o Reed (2008) relata que para superar muitas de suas limitações, a participação dos stakeholders deve ser institucionalizada, criando as culturas organizacionais que podem facilitar os processos onde os objetivos são negociados e os resultados são necessariamente incertos. Nessa luz, os processos participativos podem parecer muito arriscados, mas está cres- 
cendo a evidência que se bem desenvolvidas, esses riscos percebidos podem ser tomada boa do valor.

Friedman e Mason (2004) destacam que para analisar a tomada de decisão sobre desenvolvimento econômico deve-se centrar sobre participantes e seus interesses. O presente trabalho dos autores detalha o modelo da análise de stakeholders desenvolvido dentro dos estudos organizacionais por Mitchell, Agle e Wood, para o uso entre formuladores e investigadores de política. Demonstrando o modelo através da introdução dos subsídios para a construção de facilidades de esportes da liga principal, um mapa de stakeholders é criado para avaliar o ambiente constitutivo baseado no grau a que as partes interessadas possuem atributos da legalidade, do poder e na urgência. Com este mapa, os vários fatores situacionais são avaliados para demonstrar a utilidade da análise da parte interessada para que os responsáveis pelas decisões controlem estrategicamente os grupos constitutivos e expliquem os resultados do caso e a maneira em que as políticas são determinadas. Embora os resultados sugiram que os responsáveis pelas decisões focalizem seus recursos nas partes interessadas que possuem todos os três atributos, monitorar o ambiente é essencial.

Assim, na presente pesquisa serão utilizadosos pressupostos teóricos já expostos para elucidar os objetivos propostos na mesma.

\section{Procedimentos Metodológicos}

Em relação ao delineamento da presente pesquisa, a mesma utiliza-se de métodos qualitativos com fins descritivos com uma etapa inicial exploratória, desenvolvida via um estudo de caso.

Pela perspectiva de uma pesquisa qualitativa, o pesquisador deve ir a campo, buscando "captar" o fenômeno em estudo, a partir da perspectiva das pessoas nele envolvidas, considerando todos os pontos de vista relevantes (GODOY, 1995). No presente caso, os envolvidos são pertencentes à SETU, a saber: Secretário de Estado do Turismo, Chefe de Gabinete da SETU, a Coordenadora de Planejamento e uma técnica da Coordenadoria de Assuntos Institucionais ambas SETU, o Presidente e um Diretor da Paraná Turismo. Para Richardson (1989), a pesquisa qualitativa possibilita estudar de forma adequada a natureza dos fenômenos sociais. Minayo (1996) complementa que por meio 
dos estudos qualitativos é possível uma melhor compreensão da complexidade dos fenômenos sociais, bem como os seus significados.

Triviños (1995) define um estudo descritivo como aquele que o pesquisador pretende conhecer uma comunidade, seus traços característicos, seus valores, etc. Tais características se fazem presente na pesquisa considerando que essa pesquisa visa compreender e descrever como ocorre a atuação dos stakeholders na perspectiva da SETU. A pesquisa possui ainda caráter exploratório em função de se desejar um melhor conhecimento e delineamento dos atores atuantes na atividade do turismo à luz da metodologia de análise dos stakeholders.

Segundo Yin (2001, p. 19),

[...] em geral os estudos de caso representam a estratégia preferida quando se colocam questões do tipo "como" e "por que, quando pesquisador tem pouco controle sobre os eventos e quando o foco se encontra em fenômenos contemporâneos.

Tem-se que o objetivo da pesquisa é analisar como ocorre a atuação dos stakeholders bem como o pesquisador possui pouco controle do fenômeno.

A coleta de dados para a realização de um estudo de caso pode se basear em inúmeras fontes. A variedade de evidências, um banco de dados das evidências e o encadeamento das mesmas, aumentarão substancialmente a qualidade do estudo de caso (YIN, 2001), sendo possível estudar de maneira mais minuciosa o fenômeno desejado. No caso do presente estudo, as informações colhidas foram a partir de dados primários e secundários.

Sobre o método de pesquisa qualitativa, desenvolvendo a partir do encaminhamento de um estudo de caso, seguindo parâmetros preconizados por Yin (2001), ou seja, precisar sua pergunta de pesquisa, fazer um levantamento da literatura pertinente, elaborar uma fundamentação teórica a partir deste levantamento e preparar um plano detalhado de pesquisa.

O caso escolhido para o estudo e aprofundamento nesta investigação, compreendeu a Secretaria de Estado do Turismo do Paraná (SETU) por ser o órgão máximo do turismo na administração pública estadual. Sua escolha foi feita de forma intencional, levando-se em consideração a facilidade de acesso e a importância desse organismo para a economia regional na qual essa localidade está inserida. 
Foram realizadas entrevistas com os principais dirigentes do órgão investigado, por meio de um roteiro de entrevistas semiestruturado, focado, e composto de questões abertas (GASKELL, 2002). Nesse procedimento será introduzido o tópico e, a partir daí, a discussão será guiada por um conjunto de questões específicas. Todas as considerações relevantes obtidas por meio da análise documental foram registradas nas páginas de anotação de campo, sendo que se somando às entrevistas realizadas, complementaram as informações obtidas.

Os resultados obtidos a partir das entrevistas e da análise documental foram inicialmente verificados caso a caso, ou seja, individualmente, por cada pergunta feita. Em seguida a análise foi agrupada no sentido de responder $e$ atender a cada uma das perguntas de pesquisa.

A organização pesquisada corresponde à Secretaria de Estado do Turismo do Paraná, órgão responsável pelas políticas e gestão do turismo estadual e o processo de entrevistas ocorreu entre junho de 2009 e março de 2010. Foram entrevistadas e consultadas seis pessoas da secretaria, a saber: Secretário de Estado do Turismo, Chefe de Gabinete da SETU, a Coordenadora de Planejamento e uma técnica da Coordenadoria de Assuntos Institucionais ambas SETU, o Presidente e um Diretor da Paraná Turismo.

Quanto as características da organização investigada, foram analisadas as respostas provenientes das entrevistas e as verificações realizadas nos documentos fornecidos pela organização, como atas do Conselho Consultivo do Turismo e suas Câmaras Temáticas, planos plurianuais dentre outros.

Para análise dos dados utilizou-se a análise da enunciação proposta por Minayo (1996) que atendeu às necessidades e às peculiaridades desta pesquisa. Nesse caso, os vieses de interpretação diminuíram, na medida em que a análise dos dados foi feita em conjunção com outras percepções. A partir dessa metodologia proposta por Minayo (1996), a seguir, apresenta-se uma sinopse dos trabalhos de análise de conteúdo que foram desenvolvidos nesta pesquisa: 1 . foram realizadas as transcrições das entrevistas; 2 . foi observado que, para os propósitos deste trabalho, a qualidade do material colhido é mais relevante do que a sua quantidade e que cada fala é uma unidade básica; 3. foi realizada uma primeira leitura atenta e em profundidade de todas as falas transcritas, procurando contextualizar o que foi relatado pelo entrevistado; 4 . foi realizada nova leitura do material; 5. foram apartadas as falas similares, juntando-as em blocos distintos, reservando espaços suficientes para futuras anotações; 6 . buscou-se o significado explícito de cada uma das falas transcritas;7. a análise foi encerrada quando os dados começaram a se repetir. 
Tem-se então que ao término das entrevistas, foram realizadas as transcrições dos dados gravados, bem como a análise das informações coletadas, sendo basicamente de caráter qualitativo. Todas as considerações relevantes obtidas por meio da análise documental foram registradas nas páginas de anotação de campo, sendo que se somando às entrevistas realizadas, complementaram as informações obtidas.

\section{O Caso da Secretaria de Turismo do Paraná}

Nesta seção é apresentada a descrição geral do caso, bem como as análises $e$ as discussões dos resultados oriundos das entrevistas e da análise documental efetuada.

\subsection{Breve Histórico da Criação da SETU}

Conforme dados da SETU (2009), as primeiras tentativas de organizar e incentivar o turismo no Paraná datam do período entre 1932-1945, quando Manoel Ribas era interventor. A única iniciativa que se tem notícia é a de um grupo de curitibanos que tentou estabelecer na Ilha do Mel um clube náutico que, entretanto não tardou a desaparecer, devido à ocupação da Ilha pela marinha, graças a sua posição estratégica durante a Segunda Guerra Mundial.

Na época foi criado o Departamento Estadual de Imprensa e Propaganda (DEIP), a exemplo do que ocorria em outros estados da Federação, nos mesmos moldes do Departamento de Imprensa e Propaganda (DIP), criado no Estado Novo por Getúlio Vargas (PARANÁ, 2009).

De acordo com Paraná (2009), com o processo de redemocratização do país e o término da Segunda Guerra Mundial, a imprensa voltou as suas atividades normais, o DEIP teve que se adaptar às novas condições políticas, passando a denominar-se Departamento Estadual de Informações, incumbido de suprir a imprensa com as notícias oficiais e de promover a divulgação das realizações do governo. A evolução não parava. Havia uma necessidade de divulgar o Estado a nível tanto interno como externo, com o objetivo de prender e atrair correntes migratórias, bem como capital, para ocupação e consequente desenvolvimento regional. Em 1953 foi criada a Câmara de Expansão em substituição ao DEIP, esta manteve a Divisão de Turismo subordinada à 
Secretaria do Governo. A ação da CEE (Câmara de Expansão Econômica) preocupou-se mais em divulgar os pontos turísticos, além de dar continuidade as obras iniciadas pelo antigo DEIP.

Em 1966 surgiu o Departamento de Turismo e Divulgação, ficando o Departamento de Turismo vinculado à Secretaria de Viação e Obras Públicas e o de Divulgação agregado ao Serviço de Imprensa do Palácio do Governo. Pouco tempo depois, o Departamento de Turismo desmembrou-se e passou a constituir um departamento autônomo dentro da Secretaria de Viação e Obras Públicas. Elaborou-se então um Plano Geral de Turismo mas que não chegou a ser implantado, principalmente por faltas de verbas. (SETU, 2009)

Após, esse Departamento de Turismo foi criada a Secretaria Extraordinária do Comércio e Indústria e o Turismo passou a ser vinculado a essa Secretaria, por curto espaço de tempo, ficando em seguida afeto à Secretaria do Governo, de onde partiu a ideia da criação de um Conselho e de uma Empresa Paranaense de Turismo.

Assim, tem-se que a partir do início da década de 1960 o setor do turismo passou a ter vinculações formais conforme será detalhado de forma melhor posteriormente.

Atualmente, conforme descrito no Plano de Desenvolvimento do Turismo no Paraná 2008-2011, o Estado do Paraná ocupa uma área de 199.554 km², tendo 10,5 milhões de habitantes. Possui 34,6\% da região Sul do Brasil e 2,3\% do território nacional. Sua divisão política compreende 399 municípios, onde se destacam Curitiba, Londrina, Maringá, Cascavel, Ponta Grossa, Guarapuava, Foz do Iguaçu e Paranaguá.

Conforme dados de Paraná (2008), as regiões turísticas vão desde natureza e história no litoral; progresso e humanismo na capital, com o bucolismo e pujança da sua região metropolitana; cultura, mistério e tranquilidade nos Campos Gerais; os pinheiros e as cachoeiras gigantes no Centro-Sul; a expansão da agroindústria e da agropecuária no Norte, Noroeste e Sudoeste; e os campos cultivados da Região Oeste com as empolgantes Cataratas e o gigantismo de Itaipu em Foz do Iguaçu, fazendo o "Paraná de Todos os Roteiros".

Tem como orientação geral da Política Estadual de Turismo o processo de municipalização e regionalização do Turismo. No período de 2003-2007 o fluxo de turistas foi da ordem 7,3milhões de pessoas, cresceu 29\% de 2002 a2006. A receita gerada com o turismo no Paraná atingiu o montante de U\$1,5 bilhão, crescendo mais do que $60 \%$ no mesmo período. Por sua vez, a oferta turística 
foi ampliada na ordem de 50\%. Hoje, o mercado turístico disponibiliza mais de 90 roteiros turísticos no Paraná, que passam pelos polos turísticos - Curitiba e Foz do Iguaçu - bem como em novas opções no interior do Estado.

\subsection{Analisando as Características dos Stakeholders}

Nesta seção é realizada a análise das duas questões de pesquisa propostas a saber: quem são e quais as características dos stakeholders e quais são suas motivações e recursos disponíveis.

\subsection{Identificando os Stakeholders e a Evolução de sua Participação}

Em relação à identificação dos stakeholders da SETU verificou-se, a priori, que são as instituições que se fazem presentes no Conselho Consultivo do Paraná, ou seja, 44 membros, conforme lista a seguir:

ABAV/PR - Associação Brasileira de Agências de Viagens;

ABBTUR/PR - Associação Brasileira de Bacharéis em Turismo;

ABCMI - Associação Brasileira dos Clubes da Melhor Idade - PR;

$\mathrm{ABEOC/PR} \mathrm{-} \mathrm{Associação} \mathrm{Brasileira} \mathrm{de} \mathrm{Empresas} \mathrm{de} \mathrm{Eventos;}$

ABETA - Associação Brasileira das Empresas de Ecoturismo e Turismo de Aventura;

ABGTUR - Associação Brasileira dos Guias de Turismo;

ABIH/PR - Associação Brasileira da Indústria de Hotéis; ABLA - Associação Brasileira das Locadoras de Automóveis;

ABRACCEF - Associação Brasileira de Centros de Convenções e Feiras;

ABRAJET - Associação Brasileira de Jornalistas de Turismo - Seccional Paraná;

ABRASEL - Associação Brasileira de Bares e Restaurantes;

AMP - Associação dos Municípios do Paraná;

AMUTUR - Associação dos Municípios Turísticos do Paraná;

Associação Comercial do Paraná;

Associação de Hostels do Estado do Paraná; 
Banco do Brasil;

Caixa Econômica Federal;

Câmara Empresarial de Turismo do Paraná;

Ecoparaná;

EMATER - Empresa Paranaense de Assistência Técnica e Extensão Rural;

Federação de Convention\&Visitors Bureaux do Estado do Paraná;

FETHEPAR - Federação dos Empregados em Turismo e Hospitalidade do Estado do Paraná; Fórum de Coordenadores dos Cursos Superiores de Turismo do Paraná;

Fórum Estadual dos Secretários e Dirigentes Municipais de Turismo;

IBQP - Instituto Brasileiro da Qualidade e Produtividade;

Instituto Municipal de Turismo de Curitiba;

IPARDES - Instituto Paranaense de Desenvolvimento Econômico e Social;

ISTS - Instituto Superior de Turismo Sustentável; Itaipu Binacional;

Ministério do Turismo;

Paraná Turismo;

SEAB - Secretaria de Estado da Agricultura e do Abastecimento;

SEBRAE/PR - Serviço Brasileiro de Apoio às Micros e Pequenas Empresas;

Secretaria de Estado da Indústria, do Comércio e Assuntos do Mercosul;

Secretaria Municipal de Turismo de Foz do Iguaçu;

SEDU - Secretaria de Estado do Desenvolvimento Urbano;

SEEC - Secretaria de Estado da Cultura;

SEED - Secretaria de Estado da Educação;

SEMA - Secretaria de Estado do Meio Ambiente e Recursos Hídricos;

SETP - Secretaria de Estado do Trabalho, Emprego e Promoção Social;

SENAC/PR - Serviço Nacional de Aprendizagem Comercial;

SENAR - Serviço Nacional de Aprendizagem Rural;

SEPL - Secretaria de Estado do Planejamento e Coordenação Geral; 
SESC/PR - Serviço Social do Comércio - Paraná;

SETU - Secretaria de Estado do Turismo (Presidente);

SINDEGTUR - PR - Sindicato Estadual dos Guias de Turismo do Paraná;

SINDOTEL - Sindicato de Hotéis, Restaurantes, Bares e Similares.

Dessa forma será analisada a configuração atual dos stakeholders para compreender a atuação deles nas atividades da SETU.

\subsection{Atuação dos Stakeholders nas Atividades da SETU}

Desde a criação da SETU no final de 2002, a sua operacionalização, já em 2003, se deu de forma participativa. Para tanto os membros do Conselho Consultivo do Turismo são convocados bimestralmente, para auxiliar na definição das atividades estratégicas da SETU, via reuniões ordinárias (seis ao ano) e extraordinárias quando necessário.

A SETU possui estrutura organizacional formada pelo Secretário de Estado, Conselho Consultivo de Turismo do Estado do Paraná, Autarquia Paraná Turismo, Centro de Convenções de Curitiba, Serviço Autônomo Ecoparaná (ente de cooperação), Chefia do Gabinete, Assessoria Técnica, Unidade de Coordenação Estadual do Prodetur Sul, Diretor Geral, Núcleo de Informática e Informações, Câmaras Setoriais, Coordenadoria de Relações Institucionais e Coordenadoria de Planejamento Turístico, bem como Escritórios Regionais de Cascavel, Foz do Iguaçu e Londrina.

Para um melhor resultado dos trabalhos do Conselho, o mesmo organizou Câmaras Temáticas, agrupando-se os temas afetos à área de representatividade de cada membro, definidas pelos Conselheiros e aprovadas pelo Presidente. Tal organização se dá da seguinte forma: Segmentação do Turismo (Patrimônio Natural/Histórico Cultural); Regionalização do Turismo (Municipalização, envolvimento da sociedade, integração de ações e roteiros regionais); Qualificação do Produto (Legislação, Controle de Qualidade, Recursos Humanos); Financiamento e investimento; Promoção e Comercialização do Produto Paraná. As Câmaras Temáticas é uma forma de agrupamento por temas com o objetivo de identificar e discutir os problemas do setor, a fim de encaminhar e propor ações para o Conselho Consultivo de Turismo. Cada Câmara é constituída por representantes das entidades membros do Conselho, que tenham afinidade com o tema proposto e por outros interessados e referendados por esses Conselhei- 
ros, com o propósito de iniciar a identificação das necessidades e promover discussões em busca de soluções para o setor. (SETU, 2009)

Ao se analisar as Atas de Reuniões realizadas pelo Conselho Consultivo do Turismo desde a sua criação, verifica-se uma evolução da participação destas instituições, onde no primeiro ano da criação da SETU tinha-se uma presença média de 17,67 participantes, chegando, em 2009, a 27 participantes. Apesar da evolução verifica-se um baixo envolvimento no processo de definição/desenvolvimento das atividades turísticas no Estado, conforme pode ser verificado a seguir.

Ao se analisar a mesma lista utilizando-se como parâmetro uma nota de corte as instituições que tiveram presença em $60 \%$ das reuniões realizadas a lista de instituições seria a seguinte: ABAV/PR, ABBTUR/PR, ABEOC/PR, ABGTUR, ABIH/PR, ABRAJET, AMUTUR, Caixa Econômica Federal, Ecoparaná, FCCST PR, FESDMT, IMT de Curitiba, Itaipu Binacional, Paraná Turismo, SEBRAE/ PR, SENAC/PR, SEPL, SESC/PR, SETU e SINDOTEL. Com presença maior do que $60 \%$ temos apenas 22 instituições que se fizeram presentes. Verifica-se uma pequena evolução da participação destas (22) instituições, na qual no primeiro ano da criação da SETU tinha-se uma presença média de 68,76\%, chegando, em 2009, a 76,52\%, maior percentual desde sua criação. Dentre essas instituições verifica-se um nível de envolvimento, a priori, elevado, considerando apenas a participação nas reuniões do Conselho Consultivo.

Ainda em se tratando de questões relacionadas à identificação e participação dos stakeholders da SETU, foi solicitado aos respondentes, seis no total, que elaborassem uma listagem dos principais stakeholders da Secretaria, sem restrição da quantidade, dos quais foram identificados: Ministério do Turismo; Sebrae Paraná; Governo do Paraná; Fecomércio; ABAV/PR; ABIH; EMBRATUR - Instituto Brasileiro de Turismo; Gestores das instâncias de governança regionais/Órgãos municipais de turismo. Foram ainda citados os seguintes stakeholders: Bancada Federal do Paraná; C\&VBureau Curitiba Conselho Consultivo de Turismo e suas câmaras temáticas; Federação dos CVB; ISTS-UFPR; Senac.

Quando se compara a lista das instituições que estão mais presentes nas reuniões com aquelas que foram citadas pelos membros da SETU como os stakeholders mais importantes, chega-se a seguinte listagem por ordem alfabética: ABAV/PR; ABIH/PR; AMUTUR; Fórum Estadual dos Secretários e Dirigentes Municipais de Turismo; Instituto Municipal de Turismo de Curitiba; SEBRAE/PR; SENAC/PR; Governo do Paraná (SEPL). 
De 44 stakeholders listados inicialmente, verifica-se que a recíproca sobre a importância dos mesmos para a SETU, tem uma listagem de 8 instituições. Assim, ocorre que esses stakeholders podem ser considerados chaves para a realização dos objetivos estratégicos da SETU.

\subsection{Características dos Stakeholders}

Para levantar as características dos stakeholders da SETU selecionou-se apenas aqueles que foram citados pelos mesmos como de maior importância para a realização dos objetivos da SETU. Dessa forma, são apresentadas na tabela a seguir as características dos 8 principais stakeholders, listados pelos membros da SETU.

A seguir são descritas as características dos principais stakeholders analisadas sob a perspectiva da SETU:

a) Ministério do Turismo - Possui recursos financeiros, Técnicos, Articulação Política. Definição de Políticas (poder) e Visão Descentralizada. Seu interesse na SETU é de realizar a implementação de políticas no Paraná, do Plano Nacional do Turismo e em Ações estratégicas. A SETU busca junto a este parceiro parceria no desenvolvimento do destino Paraná e seus produtos e Apoio financeiro. Sobre as características descritas por Mitchel et al.(1997), observa-se que a instituição possui poder, legitimidade e urgência.

b) Sebrae PR - Possui recursos Financeiros, Humanos, Técnicos, Networking, e Articulação. Seu interesse na SETU está em estabelecer Parceria para o desenvolvimento das propostas regionais, Implementação Projeto Sebrae de Turismo, Legitimidade, Atuar junto à definição de políticas públicas e Atender à Política Estadual de Turismo. A SETU busca no relacionamento com o Sebrae Parceria no desenvolvimento do Plano Estadual de Turismo, Networking com empresariado, Formatação do Produto Paraná, Participação da iniciativa privada do Turismo e Recursos Financeiros. Em relação às características de Mitchel et al. (1997), verificou-se entre os respondentes que a instituição possui poder e legitimidade em relação aos seus pleitos.

c) Governo do Paraná - Possui recursos Financeiros, Humanos, Articulação e Político. Seu interesse na SETU é o Conhecimento Técnico para 
ações em parceria e que atendam ao plano de governo, Crescimento econômico e social, Importância institucional/status e Interação setorial via secretarias. Para a SETU sua importância está na Parceria com o desenvolvimento do Plano Estadual, Reconhecimento do Turismo como atividade econômica, Importância Institucional e Apoio Técnico/ político operacional. Assim como o Ministério do Turismo, quando indagados sobre as características descritas por Mitchel et al.(1997), observa-se que a instituição possui poder, legitimidade e urgência.

d) Fecomércio - Possui recursos Humanos, Financeiros, Networking e Poder. Seu interesse na SETU está relacionado à parceria para o desenvolvimento das ações do SENAC e SESC, legitimidade/apoio político e Atender à Política Estadual de Turismo. A SETU busca Parceria no desenvolvimento do Plano Estadual (qualificação), Recursos Financeiros e Legitimidade junto ao empresariado. Os informantes descreveram que a instituição possui poder, legitimidade e urgência.

e) ABAV - Possui recursos de ordem técnica. Seu interesse junto à SETU se dá pela Parceria no desenvolvimento de novos produtos para comercialização e para a realização de ações com seus representados. A SETU espera da mesma Parceria no desenvolvimento do Plano Estadual (promoção e apoio à comercialização) e Aproximação e apoio com seus representados. Sobre as características listadas por Mitchel et al. (1997), a instituição foi classificada como legítima.

f) $\mathbf{A B I H}$ - Possui recursos Técnicos e de Articulação. Interesse que possui pela SETU: parceria para a realização de ações com seus representados e Ações estratégicas. $\mathrm{O}$ interesse da SETU está na Aproximação com seus representados e no apoio a eles. Assim como a ABAV, a instituição foi classificada como legítima de acordo com Mitchel et al.(1997).

g) EMBRATUR - Possui recursos Financeiros, Técnicos e Humanos. Seu interesse na SETU é para parceria no desenvolvimento do destino Brasil (internacional) e apoio para implementação do Plano Nacional de Turismo (promoção internacional). A SETU quer da mesma parceria no desenvolvimento do destino Paraná no mercado internacional e apoio financeiro e técnico para desenvolvimento de ações no mercado internacional. Os informantes descreveram que a instituição possui poder, legitimidade e urgência. 
h) Instâncias de Governança Regional/Órgãos municipais de turismo - Seu principal recurso é o Contato direto com os atores envolvidos em cada uma das regiões turísticas. Tem interesse na SETU para ter o órgão oficial do turismo como parceiro para consolidação das instâncias com entidade representativa do turismo regional. A SETU tem interesse na mesma para ter em cada região uma entidade representativa para apoiar a estruturação e consolidação de produtos turístico, além de fomentar a política pública de municipalização e regionalização do turismo, visando tornar a região em destino turístico.

i) Secretários e Dirigentes Municipais de Turismo - Possui Recursos Técnicos e Humanos. Tem interesse da SETU na Parceria para implementação das ações municipais. O Interesse da SETU é o apoio e a parceria no cumprimento dos objetivos e metas previstos no Plano de Desenvolvimento do Turismo do Paraná. Os informantes descreveram que a instituição possui poder, legitimidade e urgência.

Tabela 1: Característica dos Stakeholders na visão da SETU

\begin{tabular}{|c|c|c|c|}
\hline Stakeholders & $\begin{array}{l}\text { Que recursos } \\
\text { este possui? }\end{array}$ & $\begin{array}{l}\text { O que ele vislumbra } \\
\text { de importante ao } \\
\text { relacionar-se com a } \\
\text { SETU? }\end{array}$ & $\begin{array}{c}\text { Qual a importância } \\
\text { para a SETU no } \\
\text { relacionamento com } \\
\text { ele? }\end{array}$ \\
\hline $\begin{array}{l}\text { Ministério do } \\
\text { Turismo }\end{array}$ & \begin{tabular}{|l|} 
Financeiros/Técnicos/ \\
Articulação Política/ \\
Definição de Políticas \\
(poder)/Visão Des- \\
centralizada
\end{tabular} & $\begin{array}{l}\text { Implementação de políti- } \\
\text { cas no PR } \\
\text { Implementação do Plano } \\
\text { Nec. Tur } \\
\text { Ações estratégicas }\end{array}$ & $\begin{array}{l}\text { Parceria no desenvolvi- } \\
\text { mento do destino Paraná } \\
\text { e seus produtos } \\
\text { Apoio financeiro/Braço } \\
\text { operacional }\end{array}$ \\
\hline Sebrae PR & $\begin{array}{l}\text { Financeiros } \\
\text { Humanos } \\
\text { Técnicos } \\
\text { Networking } \\
\text { Articulação }\end{array}$ & $\begin{array}{l}\text { Atender a Política Estadu- } \\
\text { al de Turismo } \\
\text { Parceria para o desenvol- } \\
\text { vimento das propostas } \\
\text { regionais } \\
\text { Implementação Proj. Se- } \\
\text { brae de Tur } \\
\text { Legitimidade/Definição } \\
\text { de políticas públicas }\end{array}$ & $\begin{array}{l}\text { Parceria no desenvolvi- } \\
\text { mento do Plano Estadual } \\
\text { Networking com empre- } \\
\text { sariado } \\
\text { Formatação do Produto } \\
\text { Paraná } \\
\text { Participação da iniciativa } \\
\text { privada do Tur } \\
\text { Financeiro }\end{array}$ \\
\hline
\end{tabular}

Fonte: Elaborada pelos autores deste artigo 


\begin{tabular}{|c|c|c|c|}
\hline Stakeholders & $\begin{array}{l}\text { Que recursos } \\
\text { este possui? }\end{array}$ & $\begin{array}{c}\text { O que ele vislumbra } \\
\text { de importante ao } \\
\text { relacionar-se com a } \\
\text { SETU? }\end{array}$ & $\begin{array}{c}\text { Qual a importância } \\
\text { para a SETU no } \\
\text { relacionamento com } \\
\text { ele? }\end{array}$ \\
\hline $\begin{array}{l}\text { Governo do } \\
\text { Paraná }\end{array}$ & $\begin{array}{l}\text { Financeiro } \\
\text { Humano } \\
\text { Técnico } \\
\text { Articulação } \\
\text { Político }\end{array}$ & $\begin{array}{l}\text { Conhecimento Técnico } \\
\text { para ações em parceria e } \\
\text { que atendam ao plano de } \\
\text { governo } \\
\text { Crescimento econômico } \\
\text { e social } \\
\text { Importância institucional/ } \\
\text { status } \\
\text { Interação setorial via se- } \\
\text { cretarias }\end{array}$ & $\begin{array}{l}\text { Parceria no desenvolvi- } \\
\text { mento do Plano Estadual } \\
\text { Reconhecimento do Tu- } \\
\text { rismo como atividade } \\
\text { econômica } \\
\text { Importância Institucional } \\
\text { Apoio Técnico/político } \\
\text { operacional }\end{array}$ \\
\hline Fecomércio & $\begin{array}{l}\text { Humanos/Técnico } \\
\text { Financeiro } \\
\text { Networking } \\
\text { Poder }\end{array}$ & $\begin{array}{l}\text { Atender a Política Estadu- } \\
\text { al de Turismo } \\
\text { Parceria para o desen- } \\
\text { volvimento das ações do } \\
\text { SENAC e SESC } \\
\text { Legitimidade/apoio po- } \\
\text { lítico }\end{array}$ & $\begin{array}{l}\text { Parceria no desenvolvi- } \\
\text { mento do Plano Estadual } \\
\text { (qualificação) } \\
\text { Financeiro } \\
\text { Legitimidade } \\
\end{array}$ \\
\hline ABAV & Recursos técnicos & $\begin{array}{l}\text { Parceria no desenvolvi- } \\
\text { mento de novos produtos } \\
\text { para comercialização } \\
\text { Parceria para a realização } \\
\text { de ações com seus repre- } \\
\text { sentados }\end{array}$ & $\begin{array}{l}\text { Parceria no desenvolvi- } \\
\text { mento do Plano Estadual } \\
\text { (promoção e apoio à } \\
\text { comercialização) } \\
\text { Aproximação e apoio } \\
\text { com seus representados }\end{array}$ \\
\hline $\mathrm{ABIH}$ & $\begin{array}{l}\text { Técnico } \\
\text { Articulação }\end{array}$ & $\begin{array}{l}\text { Parceria para a realização } \\
\text { de ações com seus repre- } \\
\text { sentados } \\
\text { Ações estratégicas }\end{array}$ & $\begin{array}{l}\text { Aproximação e apoio } \\
\text { com seus representados } \\
\text { Parceria }\end{array}$ \\
\hline EMBRATUR & $\begin{array}{l}\text { Financeiro } \\
\text { Técnico } \\
\text { Humano }\end{array}$ & $\begin{array}{l}\text { Parceria no desenvolvi- } \\
\text { mento do destino Brasil } \\
\text { (internacional) } \\
\text { Apoio para implementa- } \\
\text { ção do Plano Nacional } \\
\text { de Turismo (promoção } \\
\text { internacional) }\end{array}$ & $\begin{array}{l}\text { Parceria no desenvolvi- } \\
\text { mento do destino Paraná } \\
\text { e seus produtos no mer- } \\
\text { cado internacional } \\
\text { Apoio financeiro e técnico } \\
\text { para desenvolvimento de } \\
\text { ações no mercado inter- } \\
\text { nacional }\end{array}$ \\
\hline
\end{tabular}

Fonte: Elaborada pelos autores deste artigo 


\begin{tabular}{|l|l|l|l|}
\hline Stakeholders & $\begin{array}{c}\text { Que recursos } \\
\text { este possui? }\end{array}$ & $\begin{array}{l}\text { O que ele vislumbra } \\
\text { de importante ao } \\
\text { relacionar-se com a } \\
\text { SETU? }\end{array}$ & $\begin{array}{l}\text { Qual a importância } \\
\text { para a SETU no } \\
\text { relacionamento com } \\
\text { ele? }\end{array}$ \\
\hline $\begin{array}{l}\text { Secretários } \\
\text { e Dirigentes } \\
\text { Municipais }\end{array}$ & $\begin{array}{l}\text { Técnicos } \\
\text { Humanos }\end{array}$ & $\begin{array}{l}\text { Parceria na implementa- } \\
\text { ção das ações municipais }\end{array}$ & $\begin{array}{l}\text { Apoio e parceria no cum- } \\
\text { primento dos objetivos e } \\
\text { metas previstos no Plano } \\
\text { de Desenvolvimento do } \\
\text { Turismo PR }\end{array}$ \\
\hline $\begin{array}{l}\text { Instâncias de } \\
\text { Governança } \\
\text { Regional/Órgãos } \\
\text { municipais } \\
\text { de turismo }\end{array}$ & $\begin{array}{l}\text { Contato direto com } \\
\text { es atores envolvidos } \\
\text { regiões turísticas }\end{array}$ & $\begin{array}{l}\text { Ter o órgão oficial do } \\
\text { turismo como parceiro } \\
\text { para consolidação das } \\
\text { instâncias com entidade } \\
\text { representativa do turismo }\end{array}$ & $\begin{array}{l}\text { Ter en cada região uma } \\
\text { entidade representativa } \\
\text { para apoiar a estrutura- } \\
\text { ção e consolidação de } \\
\text { produtos turístico, além } \\
\text { de fomentar a política } \\
\text { pública de municipaliza- } \\
\text { ção e regionalização do } \\
\text { turismo. }\end{array}$ \\
\hline
\end{tabular}

Fonte: Elaborada pelos autores deste artigo

Verifica-se que Ministério do Turismo, Sebrae, Governo do Paraná e Fecomércio são as instituições que foram lembradas por cinco dos seis respondentes como os possuidoras de poder, legitimidade e urgência. Tal característica, quando comparada com a coluna que descreve os recursos que a mesma possui, tem-se em comum a disponibilidade de recursos financeiros das mesmas, o que é essencial para a implementação das políticas públicas para o setor. Foram listadas ainda como as possuidoras de poder, legitimidade e urgência a Embratur e os Secretários e Dirigentes Municipais de Turismo, porém por apenas dois dos respondentes o que releva que tais características dos mesmos são em menor proporção.

$\mathrm{A} \mathrm{ABAV}$ e a $\mathrm{ABIH}$ foram classificadas como portadoras de legitimidade e urgência que, comparadas com os recursos que as elas possuem, é possível verificar se as instituições possuem recursos técnicos e de articulação.

Já em relação a Instâncias de Governança Regional/Órgãos municipais de turismo tem-se que as mesmas possuem legitimidade e urgência, já que as mesmas possuem contato direto com os atores envolvidos em cada uma das regiões do Estado. 
De acordo com os respondentes verifica-se que as instituições Ministério do Turismo, Sebrae Paraná, Governo do Paraná e Fecomércio são listadas como importantes e possuidoras de recursos necessários a SETU. Porém, ao se avaliar a participação das mesmas nas reuniões do Conselho Consultivo verifica-se baixa frequência da MTUR e Fecomércio, podendo ser indicativo de comprometimento relativamente menor ao despendido pela SETU. Já no Sebrae e no Governo do Paraná, via suas Secretarias, é possível verificar um alto grau de envolvimento.

Instituições como $\mathrm{ABAV}$ e $\mathrm{ABIH}$ foram consideradas possuidoras de relativa importância e legitimidade, sendo que se observa que as mesmas retornam a SETU na mesma proporção colaborando com o desenvolvimento do Conselho Consultivo do Turismo.

Há ainda as instâncias de Governança Regional/Órgãos municipais de turismo que possuem alta importância relativa, porém, baixa participação no Conselho, a Embratur possui importância relativa para a SETU, porém, não tem cadeira junto ao Conselho, e o Instituto Municipal do Turismo de Curitiba, que não tem importância relativa alta, porém, tem participação elevada junto ao Conselho. Aqui pode-se destacar a natureza política dessa característica, já que o Governo Estadual e a Prefeitura de Curitiba são governados por legendas partidárias concorrentes o que, de certa forma, distancia os órgãos.

\subsection{Analisando a Dinâmica de Atuação dos Stakeholders}

Em relação ao processo de análise dos stakeholders, a mesma foi conduzida a partir da perspectiva da SETU, sendo que foram utilizados alguns dos parâmetros descritos por Freeman (1984), Mitroff (1983) e Reed, Graves e Dandy (2009), a saber: identificar stakeholders; diferenciar os mesmos categorizando-os; verificar relacionamentos entre stakeholders, as propostas/ motivações; identificar os recursos impostos (material, simbólico, físico, status, informacional, habilidade; e o comprometimento de ordem legal e de outros tipos).

Tomou-se como base ainda a definição clássica stakeholder de Freeman (1984, p. 46) "[...] qualquer grupo ou pessoa cujos interesses podem afetar ou ser afetados pelas realizações dos objetivos de uma organização."

No que tange ao processo de identificação dos stakeholders da SETU verifica-se que os mesmos, a priori, foram considerados todos os membros 
do Conselho Consultivo do Turismo do Paraná composto por 44 entidades. Porém verificou-se neste processo que a escolha de tais membros foi induzida pelo Ministério do Turismo que durante o processo de sua estruturação sugeriu aos órgãos estaduais responsáveis pelo turismo uma maior participação da comunidade conforme verificado a seguir:

[...] em 2002, quando nós estávamos estruturando a secretaria tinha também a estruturação do Ministério do Turismo que estava acontecendo no mesmo tempo... assim foram feitas reuniões junto aos órgãos estaduais de turismo para que nós nos adequássemos a algumas diretrizes que estariam sendo implementadas pelo Ministério... uma delas é o processo de regionalização... acabou que as instancias estaduais foram se organizando conforme estas diretrizes, que no nosso caso houve um alinhamento de nossa estrutura organizacional... [isso você pode encontrar mais informações no site do ministério, lá tem o Plano Nacional do Turismo 2003 - 2007 que fala sobre estas diretrizes [...] (COORDENADORA DE PLANEJAMENTO, 2010)

Verifica-se que tal processo pode, conforme descreve Prell, Hubacek e Reed (2009) e Lamberg, Pajunen e Parvinen (2008), ser usada para evitar conflitos, assegura-se que a marginalização de determinados grupos não esteja reforçada, e para representar razoavelmente interesses diversos. Porém, em contrapartida pode prejudicar o comprometimento de alguma entidades já que as mesmas não precisamente tem ou tinham a cultura de participação em conselhos para se determinar políticas públicas setoriais. Tal fato fica evidente ao se analisar a participação das entidades nas reuniões do Conselho, quando se observa que apenas 20 entidades tem participação superior a $60 \%$ das reuniões realizadas desde a criação da SETU.

Em relação ao diferenciar os mesmos categorizando-os, tal categorização foi feita inicialmente pelos membros da SETU, em queobservou-se homogeneidade dentre os respondentes, seis no total, o que evidencia clareza da importância dos mesmo entre a equipe. Foram listados inicialmente como os mais importantes: Ministério do Turismo, Sebra e Paraná, Governo do Paraná, Fecomércio, ABAV/PR, ABIH, EMBRATUR - Instituto Brasileiro de Turismo, Gestores das instâncias de governança regionais/Órgãos municipais de turismo. Todos com pelo menos três respondentes citando os mesmo. 
Ao ser abordado os recursos disponíveis, relacionamentos, motivações e comprometimento verifica-se que as instituições Ministério do Turismo, Sebrae Paraná, Governo do Paraná e Fecomércio são listadas como importantes e possuidoras de recursos necessários a SETU. Porém ao se avaliar a participação das mesmas nas reuniões do Conselho Consultivo verifica-se baixa frequência da MTUR e Fecomércio, podendo ser indicativo de comprometimento relativamente menor ao despendido pela SETU. Já no Sebrae e no Governo do Paraná, via suas Secretarias, verifica-se alto grau de envolvimento. Instituições como $\mathrm{ABAV}$ e $\mathrm{ABIH}$ foram consideradas possuidoras de relativa importância e legitimidade, sendo que se observa que as mesmas retornam a SETU na mesma proporção colaborando com o desenvolvimento do Conselho Consultivo do Turismo. Tem-se ainda as instâncias de Governança Regional/Órgãos municipais de turismo que possuem alta importância relativa porém baixa participação no Conselho, a Embratur que possui importância relativa para a SETU, porém, não tem cadeira junto ao Conselho, e o Instituto Municipal do Turismo de Curitiba, que não tem importância relativa alta, porém tem participação elevada junto ao Conselho. Aqui é possível destacar a natureza política dessa característica, já que o Governo Estadual e a Prefeitura de Curitiba são governados por legendas partidárias concorrentes o que, de certa forma, distancia o órgão municipal do estadual.

De maneira geral, verifica-se que no presente caso tem-se um processo flexível e transparente que busca encampar os valores envolvidos, conforme postula Reed (2008). Observa-se ainda que a participação dos stakeholders deve ser institucionalizada, o que está presente no caso da SETU, já que o mesmo está previsto em lei. Deve-se atentar, porém, aos resultados levantados por Medilanski, Chuan e Mosler (2007) que, com base em uma análise de stakeholders, os autores concluíram que o desacordo com a suposição da maioria de teorias da política, stakeholders locais consideram caminhos informais da decisão de grande importância.

De acordo com Hermans e Thissen (2009), os analistas políticos reconhecem o valor de alguma compreensão do papel dos atores em processos políticos. Essa visão geral é usada para discutir algumas das implicações para os analistas de política que estão interessados em analisar os processos incluindo vários agentes, se centrando especificamente sobre trade-offs entre a qualidade analítica e a usabilidade prática. 
Realizou-se ainda uma análise a partir das dimensões propostas por Mitchell, Agle e Wood (1997) que apresentam a proposição de um modelo sustentado em três dimensões:

(1) o poder dos stakeholders de influenciar a empresa, (2) a legalidade do stakeholder no relacionamento com a empresa, e (3) a urgência do stakeholder de reivindicação na empresa (MITCHELL, AGLE; WOOD, 1997, p. 854).

Verifica-se que Ministério do Turismo, Sebrae, Governo do Paraná e Fecomércio são as instituições que foram lembradas por cinco dos seis respondentes como possuidoras de poder, legitimidade e urgência. Tal característica, quando comparada com a coluna que descreve os recursos que a mesma possui, tem-se em comum a disponibilidade de recursos financeiros das mesmas, o que é essencial para a implementação das políticas públicas para o setor. Foram listadas ainda como possuidoras de poder, legitimidade e urgência a Embratur e os Secretários e Dirigentes Municipais de Turismo, porém por apenas dois dos respondentes o que releva que tais características dos mesmos são em menor proporção. A ABAV e a ABIH foram classificadas como portadoras de legitimidade e urgência que, comparadas com os recursos que as mesmas possuem, verifica-se as instituições possuem recursos técnicos e de articulação. Já em relação a Instâncias de Governança Regional/Órgãos municipais de turismo tem-se que as mesmas possuem legitimidade e urgência, já que as mesmas possuem contato direto com os atores envolvidos em cada uma das regiões.

Observa-se que os membros da SETU têm clareza sobre quem são os principais stakeholders, bem como os recursos que os mesmos possuem o que possibilita seguir uma constatação destacada por Friedman e Mason (2004) de que para se analisar a política da tomada de decisão deve-se centrar sobre participantes e seus interesses e que os responsáveis pelas decisões focalizem seus recursos nas partes interessadas que possuem legitimidade, poder e urgência. Ou seja, tal fato se encontra presente no referido caso o que aumenta as chances de resultados positivos das políticas a serem implementadas pela Secretaria. 


\section{Considerações Finais}

A presente pesquisa buscou analisar como é a atuação dos stakeholders no desenvolvimento de atividades estratégicas da Secretaria de Estado do Turismo do Paraná - SETU, sendo esse objetivo alcançado, ou seja, as questões de pesquisa: quem são e quais as características dos stakeholders? Quais são seus recursos e motivações? Como se dá a atuação dos stakeholders na perspectiva da SETU? foram respondidas.

Em relação a quem são os stakeholders da SETU, conforme relatado por todos os entrevistados, a priori os mesmos são os 44 membros do Conselho Consultivo do Turismo do Paraná. Porém, ao se questionar os informantes aqueles que possuem maior relevância foram identificados uma listagem com oito instituições, que podem ser consideradas chaves para a realização dos objetivos estratégicos da SETU, a saber: Ministério do Turismo, Sebrae, Governo do Paraná, Fecomércio, ABAV, ABIH, Embratur e Dirigentes Municipais de Turismo.

Dentre as oito instituições, foram descritas as suas características e recursos disponíveis, sendo que se observou que Ministério do Turismo, Sebrae, Governo do Paraná e Fecomércio são as instituições que foram lembradas por cinco dos seis respondentes como possuidoras de poder, legitimidade e urgência. Tal característica, quando comparada com a coluna que descreve os recursos que a mesma possui, tem-se em comum a disponibilidade de recursos financeiros das mesmas, o que é essencial para a implementação das políticas públicas para o setor. Foram listadas ainda como possuidoras de poder, legitimidade e urgência a Embratur e os Secretários e Dirigentes Municipais de Turismo, porém por apenas dois dos respondentes, o que releva que tais características dos mesmos são em menor proporção. A ABAV e a ABIH foram classificadas como portadoras de legitimidade e urgência que, comparadas com os recursos que as mesmas possuem, verifica-se as instituições possuem recursos técnicos e de articulação. Já em relação a Instâncias de Governança Regional/Órgãos municipais de turismo ocorre que as mesmas possuem legitimidade e urgência, já que as mesmas possuem contato direto com os atores envolvidos em cada uma das regiões.

Em relação às motivações/interesses dos stakeholders da SETU verifica-se que o Ministério do Turismo busca implementar o Plano Nacional do Turismo no Paraná; o Sebrae PR - busca estabelecer parceria para o desenvolvimento 
e implementação do Projeto Sebrae de Turismo, legitimar sua participação bem como atuar na definição de políticas públicas estaduais; o Governo do Paraná tem como interesse o conhecimento técnico para ações em parceria $e$ que atendam ao plano de governo; a Fecomércio busca parceria para o desenvolvimento das ações do Senac e Sesc e legitimidade; a ABAV e a ABIH parceria no desenvolvimento de novos produtos para comercialização e para a realização de ações com seus representados; a Embratur busca parceria no desenvolvimento do destino Brasil (internacional); e as Instâncias de Governança Regional/Órgãos municipais de turismo e os Secretários e Dirigentes Municipais de Turismo tem interesse em consolidar as instâncias com entidade representativa do turismo regional e implementar as ações municipais.

Dessa forma, tem-se que a atuação dos stakeholders junto à definição das políticas e estratégias da SETU ocorre via Conselho Consultivo e Câmaras Temáticas. Verificou-se que muitos dos membros ainda possuem baixa participação nesses órgãos colegiados Observa-se que os membros da SETU têm clareza sobre quem são os principais stakeholders, bem como os recursos que os mesmos possuem, porém há uma evolução de sua participação desde a sua criação no ano de 2003.

\section{Stakeholders Analysis applied to Public Agencies: the case of the Secretary of State for Tourism of Paraná}

\section{Abstract}

This article aims to analyze the performance of stakeholders in the development of strategic activities of the State Secretary of Tourism of Paraná (SETU), verified from the perspective of the theory of stakeholders. This was achieved is also a review of the stakeholder theory describing its conceptual evolution and models of analysis used. Regarding the research design is that it is characterized by the application of an exploratory, qualitative, developed through a single case study, represented by the state agency of tourism of Paraná (SETU). With respect to who the stakeholders are the SETU was found that those with greater relevance were identified a list with eight institutions within the Consultative Council of Tourism of Paraná. We conclude that 
the actions of stakeholders together to define policies and strategies SETU occurs via the Tourism Advisory Council and its five Thematic Chambers. It was also verified that many Council members still have low participation in these collective bodies, but there is an evolution of its participation since its inception in 2003.

Key words: Stakeholders theory. Tourism. Strategy.

\section{Referências}

COSTA, B. K. et al. A influência dos stakeholders na estratégia de órgãos públicos: o caso da diretoria de turismo de Guarulhos/SP. In: ENCONTRO DE ESTUDOS EM ESTRATÉGIA - 3Es, 4.,2009, Recife. Anais...Recife: ANPAD, 2009.

COSTA, B. K. et al. Interação dos stakeholders em organizações do turismo: o caso do órgão municipal de turismo em Guarulhos/SP. In: SEMINÁRIOS EM ADMINISTRAÇÃO - SEMEAD, 12.,2009, São Paulo. Anais... São Paulo: FEA/USP, 2009.

EMBRATUR. Estatísticas básicas de turismo. Brasília: Embratur, 2007.

FREEMAN, R. E. Strategic management: a stakeholder approach. Massachusetts: Sage, 1984.

FRIEDMAN, A. L.; MILES, S. Developing stakeholder theory. Journal of Management Studies, v. 39, n. 1, p.1-21, jan. 2002.

FRIEDMAN, M. T.; MASON, D. S. A stakeholder approach to understanding economic development decision making: public subsidies for professional sport facilities. Economic Development Quarterly, v. 18, n. 3, p. 236-254, ago. 2004.

FRIEDMAN, Andrew L.; MILES, Samantha. Stakeholder: theory and practice. New York: OxfordUnivesity Press, 2006.

GASKELL, George. Entrevistas individuais e grupais. In: BAUER, M. W.; GASKELL, G. Pesquisa qualitativa com textos, imagem e som. Petrópolis, RJ: Vozes, 2002.

GODOY, A. S. Pesquisa qualitativa: tipos fundamentais. Revista de Administração de Empresas, São Paulo, v. 35, n. 3, p. 20-29, mai./jun. 1995. 
GOMES, R. C.; GOMES, L. D. M. Who is supposed to be regarded as a stakeholder for public organizations in developing countries? Evidence from an empirical investigation in Brazilian municipalities. Public Management Review, v. 10, n. 2, 2008.

HERMANS, L. M.; THISSEN, W. A. H. Actor analysis methods and their use for public policy analysts. European Journal of Operational Research, v. 196, n. 2, Jul. 2009.

LAPLUME, André O.; SONPAR, Karan; LITZ, Reginald A. Stakeholder theory: reviewing a theory that moves us. Journal of Management, v. 34, n. 6, p. 1.1521.189, Dec. 2008.

LAMBERG, J. A.; PAJUNEN, K.; PARVINEN, P. Stakeholder management and path dependence in organizational transitions. Management Decision, v. 46, n. 5-6, 2008.

MEDILANSKI, E.; CHUAN, L.; MOSLER, H. J. Identifying the institutional decision process to introduce decentralized sanitation in the city of Kunming (China).

Environmental Management, China, v. 39, n. 5, p. 648-662, May. 2007.

MINAYO, M. C. O desafio do conhecimento: pesquisa qualitativa. São Paulo: Hucitec, 1996.

MITCHELL, Ronald K.; AGLE, Brandley R.; WOOD, Donna J. Toward a theory of stakeholder identification and salience: defining the principle of the who and what really counts. Academy of Management Review, v. 22, n. 4, p. 853-886. Oct. 1997.

MITROFF, Ian I. Stakeholders of the organizational mind: toward a new view of organizations policy making. San Francisco, California: Jossey-BassPublishers, 1983.

PARANÁ. Secretaria de Estado do Turismo do Paraná: Histórico Institucional. [2009?]. Disponível em: <http://www.setu.pr.gov.br> . Acesso em: 29 abr. 2009.

PRELL, C.; HUBACEK, K.; REED, M. Stakeholder analysis and social network analysis in natural resource management. Society \& Natural Resources, v. 22, n. 6, p. 501-518, Jul. 2009.

REED M. S. Stakeholder participation for environmental management: a literature review. Biological Conservation, v. 141, n. 10, p. 2.417-2.431, Oct. 2008. 
REED, M.S., GRAVES, A.; DANDY, N. Who's in and why? a typology of stakeholder analysis methods for natural resource management. Journal of Environmental Management, v. 90, n. 5, p. 1.933-1.949, Apr. 2009.

RICHARDSON, Roberto Jarry. Pesquisa social: métodos e técnicas. São Paulo, Atlas, 1998.

YIN, Robert K. Estudo de caso: planejamento e métodos. Porto Alegre: Bookman, 2001. 